\title{
African Easterly Waves and Their Association with Precipitation
}

\author{
Guojun Gu, Robert F. Adler, George J. Huffman, and Scott Curtis
}

\section{Popular Summary}

African easterly waves are important synoptic phenomena during the northern summer over West African continent. Good knowledge of these waves and their variability will definitely enhance our understanding of persistent African drought and climate change. Also, most of the Atlantic hurricanes (about $80 \%$ ) originated from these waves. In this study, we explored the relationships between these waves' dynamic structure and accompanying convection and precipitation. NCEP/NCAR Reanalysis $850 \mathrm{mb}$ meridional wind component is used to represent the wind perturtation and TRMM rainfall data to denote the surface rainfall varitions. Wavelet spectrum and cross-spectrum analyses are used to quantify the wave and rainfall perturbation intensity, and their relations. Based on these analyses, wave structure and associated precipitation are further inferred. It is found, the wave structure and associated convective coupling might be latitude-dependent. In the northern Sahel region, convection and precipitation may not be a positive factor for the wave development. Intense positive correlations are only seen south of about $15^{\circ} \mathrm{N}$. Furthermore, the strongest positive relations between the waves and convection are observed primarily during July-September. The inferred horizontal wave structure is confirmed by a 5-year composite analysis. 


\section{African Easterly Waves and Their Association with Precipitation}

Guojun $\mathrm{Gu}$

Goddard Earth Sciences and Technology Center, University of Maryland

Baltimore County, and Laboratory for Atmospheres, NASA/Goddard Space

Flight Center, Greenbelt, MD, USA.

Robert F. Adler

Laboratory for Atmospheres, NASA/Goddard Space Flight Center, Greenbelt, MD, USA.

George J. Huffman

Science Systems and Applications, Inc., Lanham, MD, and Laboratory for Atmospheres, NASA/Goddard Space Flight Center, Greenbelt, MD, USA.

Scott Curtis

Joint Center for Earth Systems Technology, University of Maryland

Baltimore County, and Laboratory for Atmospheres, NASA/Goddard Space Flight Center, Greenbelt, MD, USA.

Guojun Gu, Code 912, Goddard Space Flight Center, Greenbelt, MD 20771, USA. (ggu@agnes.gsfc.nasa.gov) 


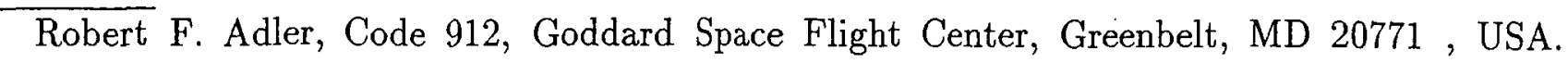
(adler@agnes.gsfc.nasa.gov)

George J. Huffman, Code 912, Goddard Space Flight Center, Greenbelt, MD 20771 , USA. (huffman@agnes.gsfc.nasa.gov)

Scott Curtis, Code 912, Goddard Space Flight Center, Greenbelt, MD 20771 , USA. (curtis@agnes.gsfc.nasa.gov) 
Abstract. Summer tropical synoptic-scale waves over West Africa are quantified by the $850 \mathrm{mb}$ meridional wind component from the NCEP/NCAR reanalysis project. Their relationships with surface precipitation patterns are further explored by applying the data from the Tropical Rainfall Measuring Mission (TRMM) satellite in combination with other satellite observations during 1998-2002. Evident wavelet spectral power peaks are seen within a period of $2.5-6$ days in both meridional wind and precipitation. The most intense wave signals in meridional wind are concentrated along $15^{\circ} \mathrm{N}-$ $25^{\circ} \mathrm{N}$. Wave signals in precipitation and corresponding wavelet cross-spectral signals between these two variables, however, are primarily located at $5^{\circ} \mathrm{N}-$ $15^{\circ} \mathrm{N}$, the latitudes of major summer rain events.

There is a tendency for the perturbations in meridional wind component to lag (lead) precipitation signals south (north) of $15^{\circ} \mathrm{N}$. In some cases, either an in-phase or out-of-phase relationship can even be found between these two variables, suggesting a latitude-dependent horizontal structure for these waves and probably implying two distinct wave-convective coupling mechanisms. Moreover, the lagging relationship (and/or the out-of-phase tendency) is only observed south of $15^{\circ} \mathrm{N}$ during July-September, indicating a strong seasonal preference. This phase relationship is generally consistent with the horizontal wave structures from a composite analysis. 


\section{Introduction}

Westward-propagating synoptic-scale waves over West Africa, commonly called African Easterly Waves (AEWs), are very important weather phenomena during the boreal summer. They can organize and effectively modulate precipitation over western African continent, and evolve into tropical cyclones under certain favorable circumstances when they move into the Atlantic Ocean [e.g., Carlson, 1969a, b; Burpee, 1972, 1974, 1975; Reed et $a l$, , 1977].

Various surface and upper air data, particularly the data from the Global Atmospheric Research Program (GARP) Atlantic Tropical Experiment (GATE), and satellite infrared (IR) observations have widely been applied to extract synoptic-scale wave signals and characterize their spatial structures through spectral and composite analyses, respectively [e.g., Burpee, 1974; Reed et al., 1977; Duvel, 1990]. Generally encompassing a period of $3-8$ days, these synoptic-scale waves propagate westward at a speed of $5-10 \mathrm{~ms}^{-1}$, yielding a wavelength on the order of $1000-5000 \mathrm{~km}$. Maximum wave amplitude is in the meridional wind component and located in the $850-650 \mathrm{mb}$ layer [e.g., Burpee, 1972; Reed et al., 1977]. Their spatial structures and particularly relations with cloudiness and/or precipitation are emphasized [e.g., Carlson, 1969a, b; Burpee, 1974; Reed et al., 1977; Chen and Ogura, 1982; Duvel, 1990; Diedhiou et al., 2001]. It is found that, in general, two perturbation centers associated with these waves actually exist. (i) One is south of about $10^{\circ} \mathrm{N}$ always accompanying moist convection. Maximum northerly and southerly wind components in the lower layer occur before and after the wave trough, respectively. Most intense upward motions occur within, and somewhat ahead of the wave trough (corresponding to intense convergence near the surface in the region just ahead 
of the trough), where maximum precipitation is always observed. Weakest precipitation, however, is found in and ahead of the wave ridge. (ii) The second center of wind perturbation is located between $10^{\circ} \mathrm{N}-20^{\circ} \mathrm{N}$ not necessarily with precipitation or even cloud. Most precipitation events occur in the southerly wind and near the ridge zone, suggesting the essential role of moisture transport associated with the low-level southerly Monsoon flow. At and near the wave trough zone, moist convection and precipitation are highly suppressed due to the deficiency of moisture.

Duvel [1990] explored the relationships between easterly waves and cloudiness using the ECMWF analysis and satellite InfraRed (IR) observations. He found that the 850 $m b$ meridional wind and cloudiness are of opposite phase in the regions south of $12.5^{\circ} \mathrm{N}$ and north of $15^{\circ} \mathrm{N}$. He then suggested that two distinct convective feedback mechanisms may exist in the southern InterTropical Convergence Zone (ITCZ) (positive) and northern Saharo-Sahelian (negative) regions, respectively. Diedhiou et al. [2001] reached a similar conclusion by showing composited horizontal wave structure and associated precipitation patterns. However, some earlier studies [e.g., Carlson, 1969a, b] did not show any preferred position of cloudiness relative to the wave trough axis. A cross-spectral analysis between the meridional wind and specific humidity in Burpee [1972] failed to infer any preference of convection relative to the wave structure. Although it can be argued that this inconsistency might be due to the poor quality and limitations of earlier observations, it is worthwhile to further examine whether there is a direct coherent relationship between the meridional wind and precipitation perturbations, especially with high-quality, consistent satellite rainfall observations, such as the Tropical Rainfall Measuring Mission (TRMM) data products. Undoubtedly, it will enhance our understanding of easterly 
waves' structure and their interaction with convection. This is the primary motivation for this study. If a latitude-dependent or even opposite phase shift truly exists between the low-level meridional wind and cloudiness within the synoptic-scale domain (Here referred to a time scale of $2.5-10$ days), wave-convective coupling mechanisms may also be latitude-dependent based on the current understanding of wave structure [e.g., Reed et al., 1977]. Furthermore, the phase relationship may have an evident seasonal shift due to intense wave-convection interaction during the boreal summer, particularly in late summer season [e.g., Chen and Ogura, 1982; Moustaoui et al., 2002].

Details of the datasets and method (a 1-d wavelet analysis) are described in section 2. In section 3 , the results from wavelet spectral and cross-spectral analyses are presented, along with a composite analysis. Finally, conclusions and implications of the study are given in section 4.

\section{Data and Methodology}

Daily $850 \mathrm{mb}$ meridional wind component from the National Centers for Environmental Prediction (NCEP) and National Center for Atmospheric Research (NCAR) reanalysis project [Kalnay et al., 1996] is used to quantify the synoptic-scale waves over West Africa during the boreal summer. Archived on a $2.5^{\circ} \times 2.5^{\circ}$ grid, only data from 1998 to 2002 are used corresponding to the availability of current TRMM gridded products.

TRMM product $3 \mathrm{~B} 42$ is applied to extract synoptic-scale wave signals from satelliteobserved surface rainfall. The existence of synoptic-scale signals in precipitation itself may partially indicate these waves' modulation of surface rainfall. This dataset is produced by using (nearly) coincident TRMM Combined Instrument (TCI) [the combined algorithm using both the TRMM Microwave Imager (TMI) and Precipitation Radar (PR)] and 
Visible and InfraRed Scanner (VIRS) data, to calibrate the geo-IR rain rate [Adler et al., 2000], providing much better rain rate estimates than simple fixed-calibration geo-IR estimates, but with the same superior time sampling. The current daily dataset (3B42) is on a $1^{\circ} \times 1^{\circ}$ grid, covers a global belt from $40^{\circ} S-40^{\circ} N$, and extends from January 1,1998 to December 31, 2002. Detailed algorithm and other related TRMM product descriptions can be found in Kummerow et al., [2000]. In this study, to fulfill our objectives, rainfall data are interpolated onto the $2.5^{\circ} \times 2.5^{\circ} \mathrm{NCEP} / \mathrm{NCAR}$ grid. Also, to avoid the affect of the western coastal region where much more intense summer rainfall and wave activity are always observed, our study will focus on the interior West Africa, i.e., $0-30^{\circ} \mathrm{N}$ and $5^{\circ} \mathrm{W}-2.5^{\circ} \mathrm{E}$.

A 1-d wavelet analysis method using Morlet wavelets is applied to quantify synopticscale wave signals in both $850 \mathrm{mb}$ meridional wind and surface rainfall. Wavelet analysis is becoming a common and powerful tool for analyzing localized variations of waves in a time series [e.g., Lau and Weng, 1995; Torrence and Compo, 1998]. The 1-D wavelet transform uses generalized local basis functions (wavelets) to decompose a time series into time-frequency space. This decomposition can determine dominant wave modes and their variability in both time and frequency. Details can be found in Lau and Weng [1995] and Torrence and Compo [1998]. Besides estimating wavelet power spectra of $850 \mathrm{mb}$ meridional wind and surface rainfall separately, wavelet cross-spectra and phase-differences between these two variables are estimated and applied to interpret their physical relationship using a similar computation procedure described in Torrence and Compo [1998]. 


\section{Results}

\subsection{Mean Wavelet Spectra and Cross-Spectra}

Wavelet global spectra of $850 \mathrm{mb}$ meridional wind $\left(P_{v}\right)$ and precipitation $\left(P_{r}\right)$, averaged approximately from June to October (Day $150-300)$ and over West Africa $\left(5^{\circ} \mathrm{N}-20^{\circ} \mathrm{N}\right.$, $\left.5^{\circ} W-2.5^{\circ} E\right)$, are depicted in Figure 1. Evident spectral peaks are observed within a period band $T=3-6$ days in both variables and in these five years, showing the existence of classic AEWs [e.g., Burpee, 1972, 1974; Reed et al., 1977]. In general, only one spectral peak can be seen in $P_{v}$ at $T=4-5$ days, with an exception of 2001 in which another one appears around $T=6-9$ days. This second peak may correspond to longer-period easterly waves discovered in past studies [e.g., Diedhiou et al., 1998]. $P_{r}$ rarely has a peak at the same period as $P_{v}$ except in 2000 in which they have an identical peak at approximately $T=4$ days. Possibly manifesting more variable fluctuations in precipitation, two or more spectral peaks generally appear in $P_{r}$, and much more spectral power are observed in the relatively shorter-period domain $(T<4$ days $)$ than in $P_{v}$. Moreover, spectral peaks in $P_{r}$ can even be seen within $T<3$ days (in 1998, 2000 and 2002). This might suggest a projection of smaller-scale mesoscale precipitating systems or even random convection onto the time-period space, although daily precipitation data can not properly represent these perturbations. Longer-period wave signals $(T \sim 7$ days $)$ in $P_{r}$ can also be observed in 2002 .

Wavelet cross-spectra $\left(C_{v r}\right)$ between $850 \mathrm{mb}$ meridional wind and precipitation have a peak at $T=3-6$ days in these five years [Figure 2], confirming the coupling of wave Figure 2 dynamics and convection. Based on the assumptions of a "red noise" spectrum [Gilman et $a l ., 1963$ ] and the $\chi^{2}$ distribution of wavelet spectra [Torrence and Compo, 1998], this $C_{v r}$ 
GU ET AL.: AFRICAN EASTERLY WAVES AND THEIR ASSOCIATION WITH PRECIPITATION 9 peak can easily reach the $95 \%$ level of significance. A second peak is seen at $T=6-9$ days in 2001 and 2002, coincident with the similar ones in $P_{v}$ and $P_{r}$, respectively. As shown in the past studies [e.g., Diedhiou et al., 1998], these longer-period waves do occasionally appear in some years and can even modulate surface precipitation, but not in every year. They are proposed to be formed from an interaction between the classic AEWs $(T=3-6$ days $)$ and the strong anticyclonic circulation north of the African Easterly Jet (AEJ) [Diedhiou et al., 1998, 1999 and 2001]. Diedhiou et al. [1999] showed that these longer-period waves are more intermittent than the classic AEWs, their corresponding wind field has both similar and contrasting characteristics, and they are generally located along $17.5^{\circ} \mathrm{N}$ north of the main rain belt. Furthermore, Grist [2002] showed that they may become more active in late summer and possibly in wet years. Since their spectral signals only appear in 2001 and 2002 and not simultaneously in both $P_{v}$ and $P_{r}$, here we will primarily focus on the waves within a period range of $T=2.56-6.08$ days [vertical dashed lines in Figure 2].

Figure 2

\subsection{Latitudinal Distribution}

For $850 \mathrm{mb}$ meridional wind, most spectral signals within the period range of $T=$ $2.56-6.08$ days are located along $15^{\circ} \mathrm{N}-25^{\circ} \mathrm{N}$ [Solid lines in Figure 3], indicating Figure 3 the most intense wave activity region in dynamic fields. This is generally consistent with previous results [e.g., Reed et al., 1977; Duvel, 1990]. A second maximum appears near $5^{\circ} \mathrm{N}-7.5^{\circ} \mathrm{N}$ except in 2000 in which the maximum tends to approach the equator, showing some wave activities to the south. It is of interest to note the existence of a minimum near $10^{\circ} \mathrm{N}$ which is actually the location of the most intense spectral signals in precipitation within the same period band [Dashed lines in Figure 3]. Intense wave signals 
in precipitation are concentrated at $5^{\circ} N-15^{\circ} \mathrm{N}$, approximately the mean latitudes of the ITCZ rain belt during the boreal summer [e.g., Gu and Zhang, 2002]. Two reasons may account for the discrepancies between the latitudes of maximum spectral signals in $850 \mathrm{mb}$ meridional wind and precipitation. First, under an extremely dry environment north of about $15^{\circ} \mathrm{N}$ over West Africa, easterly waves may not be coupled with moist convection. Dynamic instability of the ambient flow (i.e., the AEJ) is the sole energy source and this may limit their impact on the rainfall within the ITCZ, even though moist convection may affect these waves through an effective, indirect influence on the AEJ [Thorncroft and Blackburn, 1999]. Second, part of the waves may modulate the precipitation over a much larger area through their latitude-dependent structure, which means that positive wave-convective coupling can be effective only in the southern part of dynamic fields where moisture is plentiful during the boreal summer [e.g., Thorncroft and Rowell, 1998]. Reed et al. [1977] also reported a southward tendency of convection and precipitation relative to wave dynamic centers. The results presented in the following subsections seem to support the second case. Apparently detailed case studies are needed to further clarify these mechanisms.

Latitudinal profiles of mean cross-spectra $\left(C_{v r}\right)$ are illustrated in Figure 4. The maxima Figure 4 of $C_{v r}$ are located at $5^{\circ} \mathrm{N}-15^{\circ} \mathrm{N}$, implying that the most intense wave-convective coupling occurs within the ITCZ rain belt, concomitant with the most intense wave signals in precipitation.

To further explore the relationship between the perturbations in meridional wind field and precipitation, their phase-differences are estimated within the synoptic-scale domain. Figure 5 illustrates the number distributions of grid points as function of phase-difference 
during July-September. Negative (positive) phase-difference values indicate that the perturbation signals in precipitation lead (lag) those in meridional wind component. The phase difference Phase $_{v r}=0^{\circ}\left( \pm 180^{\circ}\right)$ represents an in- (out-of-) phase relationship between these two kinds signals. As southerly wind is literally considered positive, Phase $_{v r}=0^{\circ}$ is reasonably assumed to correspond to a zone in which the maximum southerly flow and precipitation perturbations are colocated. The wave trough and ridge are thus located at Phase $_{v r}=-90^{\circ}$ and $+90^{\circ}$, respectively, corresponding to the cyclonic structure of waves [e.g., Reed et al., 1977]. A northward transition pattern in phasedifference seems to exist [Figure 5]. Along the latitudes of $7.5^{\circ} \mathrm{N}, 10^{\circ} \mathrm{N}$, and $12.5^{\circ} \mathrm{N}$, there is a peak around $-180^{\circ}$ to $-120^{\circ}$, suggesting a tendency of out-of-phase. This is qualitatively consistent with Tai and Ogura (1987) which reported a phase difference of $-90^{\circ}$ to $-110^{\circ}$ for the easterly waves along $11.25^{\circ} \mathrm{N}$ in the eastern Pacific. Hence the positive precipitation anomalies related to the waves are ahead of the wave trough and tend to be close to the anomalous northerly flow zone. This tendency becomes weaker along $15^{\circ} \mathrm{N}$ with another weak peak appearing near $0^{\circ}$. At the latitudes of $17.5^{\circ} \mathrm{N}$ and $20^{\circ} \mathrm{N}$, the strongest peak is located between $0^{\circ}$ to $+60^{\circ}$, implying an in-phase relationship. Positive precipitation anomalies caused by the waves are within the anomalous southerly flow zone, and actually tend to be near the wave ridge.

Since we did not distinguish the stronger wave signals from the weaker ones in Figure 5 , it is of interest to further examine whether a similar pattern could be found between the convective-coupled wave intensity (quantified by $C_{v r}$ ) and phase-difference. Figure 6 shows the corresponding relationship between the wavelet cross-spectral power and the phase-difference for these synoptic-scale waves. A strong latitude-dependent relationship 
can also be seen, qualitatively consistent with Figure 5 . In the south (along $7.5^{\circ} \mathrm{N}, 10^{\circ} \mathrm{N}$, Figure 5 and $\left.12.5^{\circ} \mathrm{N}\right)$, most stronger systems tend to be located at $-180^{\circ}$ to $-60^{\circ}$, and $+180^{\circ}$ to $+120^{\circ}$. Considering the periodic pattern of the waves, the positive precipitation anomalies tend to be near the anomalous northerly flow zone and some of them are closer to the wave trough zone than in Figure 5. There are also some stronger systems with an inphase relationship and tending to be close to the ridge zone. Along $15^{\circ} \mathrm{N}$, two major peaks occur at $-60^{\circ}$ and between $0^{\circ}$ to $+60^{\circ}$. In the north (along $17.5^{\circ} \mathrm{N}$ and $20^{\circ} \mathrm{N}$ ), the strongest peak is seen near Phase $_{v r}=0^{\circ}$, suggesting that those most intense systems have an in-phase relationship between the perturbations in precipitation and meridional wind component. However, some stronger systems can also be found between $P$ hase $e_{v r}=-120^{\circ}$ to $+120^{\circ}$, which tend to be near the wave trough and the northerly flow zone.

Based on the results from Figures 5 and 6 , we may conclude that even though some of the stronger systems show an inconsistency, a latitude-dependent phase-shift does exist Figures and the major contributions to this shift are from the stronger ones. This contrasting nature strongly suggests that the dynamic structure of easterly waves and their association with convection may be totally different between south and north of about $15^{\circ} \mathrm{N}$, consistent with previous studies [e.g., Duvel, 1990; Diedhiou et al., 2001]. To the south of about $15^{\circ} \mathrm{N}$, convection and precipitation lead the $850 \mathrm{mb}$ meridional wind and approach the wave trough zone. Hence, diabatic heating associated with convection and precipitation tend to enhance wave development, if a mid-tropospheric warm core structure near the trough zone is assumed [e.g., Fig. 9b in Reed et al., 1977] and if vortex-stretching is indeed in effect below $700 \mathrm{mb}$ where a cold core is always seen [Thorncroft and Rowell, 1998]. North of $15^{\circ} \mathrm{N}, 850 \mathrm{mb}$ meridional wind perturbations lead postitive surface precip- 
itation anomalies. Convection and precipitation tend to be a little behind the maximum southerly flow, giving a preferred location near the wave ridge. Thus, diabatic heating may be ignorable for wave development and the feedback may even be negative since the convection and precipitation do not occur near the wave trough zone.

\subsection{Temporal Variation}

Most intense wave activities occur during late July-September [Figure 7]. In addition to the evident spectral signals observed in both $850 \mathrm{mb}$ meridional wind and precipitation, mean wavelet cross-spectrum show a strong correlation between them, particularly in August, though these strong spectral peaks are actually dominated by several individual intense easterly waves in 1999, 2000, 2001 and 2002 [Figure 8]. Strong wave signals in precipitation are also seen in the early summer, probably a consequence of intense precipitation associated with African Monsoon near the coastal line in the Gulf of Guinea (about $5^{\circ} \mathrm{N}$ ). These signals may be associated with eastward-propagating Kelvin waves [Wheeler and Kiladis, 1999], since no similar meridional wind perturbations are seen. Intense Monsoon rainfall during this time period corresponds to the first precipitation peak before the main rain belt "jumps" to the north to form a second peak along $10^{\circ} \mathrm{N}$ as shown in Sultan and Janicot [2000], Le Barbe et al. [2002] and Redelsperger et al. [2002]. Before July, as wave signals in $850 \mathrm{mb}$ meridional wind are weaker and far away from the moist rainy region, relatively weaker cross-spectral power is seen as expected.

Detailed seasonal variations in easterly wave activities are further displayed in Figure 8 for each year. Consistent with the behaviors of 5-yr-mean spectral power, most intense wave signals are generally observed during July-September. However, easterly waves show evident year-to-year variability not only in their wave signals but also in their interaction 
with convection. In 1998, persistent easterly wave activities in $850 \mathrm{mb}$ meridional wind last from June to October despite two breaks appearing in July and September, respectively. However, $P_{r}$ and $C_{v r}$ during the peak season (August-September) are only comparable to or even weaker than in early summer and fall (i.e., June and October). In contrast, several strong power peaks in $P_{v}, P_{r}$ and $C_{v r}$ co-existed during August-September in 1999 and 2000, emphasizing the intense individual wave activities and associated convective coupling. In 2001, strong power peaks can be seen in $P_{v}$ but not in $P_{r}$ and $C_{v r}$, probably suggesting the presence of non-convective-coupled wave signals. In 2002 , intense wave activity can be observed in $P_{v}, P_{r}$ and $C_{v r}$ as early as in June. Also, intraseasonal variability in $P_{v}, P_{r}$ and $C_{v r}$ exists in all five years, and spectral power peaks in different years evidently appeared in different months. Intraseasonal variability in easterly waves might be helpful to understand their interannual variability, especially when an almost equal wave activity, quantified by the seasonal mean, is found in some years. Undoubtedly, it may also be beneficial to clarify the relationship between easterly waves and Atlantic hurricane activity on both intraseasonal and interannual time scales [Landsea, 1993].

Evident latitudinal preferences of $P_{v}, P_{r}$ and $C_{v r}$ have been shown in last subsection [Figures 3 and 4]. Figures 5 and 6 clearly display the existence of two different phaserelationships in $850 \mathrm{mb}$ meridional wind and precipitation in the southern and northern West Africa. Seasonal variations in easterly wave activities may also be latitudedependent. Between $15^{\circ} \mathrm{N}-20^{\circ} \mathrm{N}$ [Left panel in Figure 9], less evident seasonal cycles are found in $P_{v}$ along with a much stronger seasonal preference of wave activity in precipitation $\left(P_{r}\right)$. Also, the peaks in $P_{v}$ do not often correspond to those in $P_{r}$. Thus, most intense wave-convective interaction occurs during late July-September when plenti- 
ful moisture is transported to the northern West Africa due to the ITCZ's seasonal march. Along $5^{\circ} \mathrm{N}-10^{\circ} \mathrm{N}$ [Right panel in Figure 9], $P_{r}$ shows a preference to the early summer season. In contrast, wave activities quantified by $850 \mathrm{mb}$ meridional wind $\left(P_{v}\right)$ primarily occur during August-September. This seasonal preference of $P_{v}$ seems to suggest a southward shift or an extension of easterly wave activity zone during the peak season which needs to be clarified in the future.

Two distinct wave-convection coupling relationships and preferred latitudes are inferred from the phase-differences between $850 \mathrm{mb}$ meridional wind and precipitation in the last subsection. Here we further explore whether this relationship has a seasonal tendency. Figure 10 illustrates the number distribution of grid points as function of Phase $_{v r}$ during May-June. Compared to Figure 5, large differences are seen in the south along $7.5^{\circ} N$, Figure 10 Figure 5 $10^{\circ} \mathrm{N}$, and $12.5^{\circ} \mathrm{N}$. No evident peak can be found at the latitudes of $7.5^{\circ} \mathrm{N}$ and $10^{\circ} \mathrm{N}$ in May-June. At $12.5^{\circ} \mathrm{N}$, the peak is even located between $0^{\circ}$ to $120^{\circ}$, quite different than in Figure 5. To the north $\left(15^{\circ} \mathrm{N}, 17.5^{\circ} \mathrm{N}\right.$, and $\left.20^{\circ} \mathrm{N}\right)$, qualitatively similar patterns can be found as in Figure 5. Hence, a strong seasonal variation in Phase $e_{v r}$ only exists south Figure 5 of $15^{\circ} \mathrm{N}$

Thus, the seasonal variations of wave signals and their convective coupling heavily depend on the seasonal migration of major rain events within the ITCZ. In the boreal spring and early summer, most of the precipitation events over West Africa occur south of $10^{\circ} \mathrm{N}$ near the Guinea coast, and easterly wave signals in $850 \mathrm{mb}$ meridional wind are always located north of $15^{\circ} \mathrm{N}$ [Figures 3 and 9] and much weaker than in the late summer [Figures 7, 8 and 9]. Thus, a connection may not easily be built between wave activities Figures and precipitation during this time period. Precipitation events may occassionally be 
observed north of $10^{\circ} \mathrm{N}$; however, they are primarily located in the southerly flow and tend to be near the wave ridge zone, and may actually dampen wave development. The same type of situations are evident in the boreal fall when the ITCZ rain belt retreats back to the south. During July-September, in contrast, the ITCZ moves to the north accompanying an enhanced northward transport of moisture, along with a possible southward shift of wave activity quantified by dynamic fields as inferred from Figure 9 . Waves become much more active, and an interaction between waves and convection becomes possible. The outof-phase relationship between the perturbations in precipitation and meridional wind field becomes dominant south of $15^{\circ} \mathrm{N}$ [Figures 5 and 6 ], showing a positive wave-convection interaction within the ITCZ rain belt.

Figures

\subsection{Composite Structure}

To confirm the inferred horizontal structures in the preceding subsections, the composite patterns are calculated based on two reference points: $\left(10^{\circ} \mathrm{N}, 0^{\circ} \mathrm{E}\right)$ and $\left(17.5^{\circ} \mathrm{N}, 0^{\circ} \mathrm{E}\right)$. The selection of these two reference latitudes is based on the spectral maxima in Figures 3 and 4 . The five daily $850 \mathrm{mb}$ meridional wind component time series at each reference point during July-September are filtered with a Lanczos filter between 2.56 and 6.08 days. As in Diedhiou et al. [1999], a maximum meridional wind greater than $+0.5 \mathrm{~ms}^{-1}$ is used as a threshold to determine the dates for easterly wave activity. Unfiltered $850 \mathrm{mb}$ zonal and meridional wind components, $700 \mathrm{mb}$ vertical velocity, and precipitation are then averaged for all the chosen dates to form the total composite patterns. Temporal mean values for each variable during July-September are further subtracted to show the wave perturbation structures [Figure 11].

Figure 11 
The composite maps generally agree with previous results [e. g., Reed et al., 1977; Diedhiou et al., 1999]. South of $15^{\circ} \mathrm{N}$, positive (negative) precipitation anomalies are seen in the northerly (southerly) flow, and before (behind) the wave trough. These positive (negative) precipitation anomalies are generally colocated with ascending (descending) motions, though a location shift is seen between these two variables. North of $15^{\circ} \mathrm{N}$, negative precipitation perturbations are primarily observed in the northerly flow, before or right on the wave trough zone. Positive precipitation can mostly be found in or behind the southerly flow area, and tends to be located near the ridge zone [especially clear in Figure 11a] except that a positive precipitation zone extending from the south is ahead of the southerly wind region in Figure 11b. Despite much weaker precipitation perturbations than in the south, most ascending (descending) areas are colocated with negative (positive) precipitation anomalies. This pattern probably suggests that the vertical motions in the waves are primarily contributed from other dynamic factors, such as the AEJ, upper tropospheric easterly jet (TEJ), etc., not from convective heating, and precipitation thus is contributed by random convective systems which are fed by the low-level moist southerly flow. While there may be some inconsistency between the NCEP/NCAR reanalysis and directly observed wind fields [Smith et al., 2001] and the composite analysis may also depend on the selection of reference latitudes [Duvel, 1990], composited features provide a perceivable and reasonable description of wave structure. It is of interest to note that no major inconsistency is found in Figure 11a and b. An opposite precipitation anomaly (antisymmetric) pattern between south and north of $15^{\circ} \mathrm{N}$ and its relevance to the dynamic fields support our inference from the wavelet cross-spectrum analysis. 


\section{Summary and Concluding Remarks}

Summer synoptic-scale waves and their relations with convection and precipitation over West Africa during 1998-2002 are explored using the NCEP/NCAR reanalysis $850 \mathrm{mb}$ meridional wind component and TRMM precipitation observations. Evident wave signals exist in both fields and are primarily within a period of $2.5-6$ days [Figure 1]. Longerperiod waves $(T>6$ days) are observed in the $850 \mathrm{mb}$ meridional wind and precipitation but only in 2001 and 2002, suggesting that they may only occasionally appear and have an intermittent impact on convection and precipitation. Most intense wave signals quantified by the $850 \mathrm{mb}$ meridional wind are located at $15^{\circ} \mathrm{N}-25^{\circ} \mathrm{N}$, while those from precipitation tend to be near the mean ITCZ rain belt $\left(5^{\circ} \mathrm{N}-15^{\circ} \mathrm{N}\right)$ [Figure 3]. Strong wave-convective interactions during the boreal summer, particularly in August and September, are inferred from a wavelet cross-spectrum analysis between these two variables [Figures 2, 4, and 7]. Maximum mean wavelet cross-spectra are seen at the mean latitudes of the ITCZ rain belt [Figure 4].

Figures

Figure 4

Two kinds of phase-relations exist between the perturbations in the $850 \mathrm{mb}$ meridional wind and precipitation within a period of $2.5-6$ days during July-September [Figures 5 and 6], confirmed by a 5 -year composite analysis [Figure 11]. North of about $15^{\circ} \mathrm{N}$, meridional wind perturbations and precipitation anomalies tend to be in-phase, indicating the maximum precipitation occurs at or just behind the maximum southerly wind Figures and approaches the wave ridge zone. This relative location between wave structure and precipitation may suggest an ignorable positive (or even a dampening) effect of convective diabatic heating on wave development and the role of moist southerly wind in the formation of convection and precipitation in this region. South of $15^{\circ} N$, inverse relations 
exist. Meridional wind perturbations lag positive precipitation anomalies, and they tend to be out-of-phase, so that the maximum precipitation is located near the wave trough zone. Convective diabatic heating therefore tends to enhance the development of these easterly waves with regard to their wind structure [e.g., Reed et al., 1977]. This relation may also be understood through a vortex-stretching mechanism suggested by Thorncroft and Rowell [1998], considering the existence of a cold core in the lower-troposphere. The results here lend strong evidence to the conclusions made in Duvel [1990]. Moreover, an evident seasonal shift of phase-difference between the perturbations in the $850 \mathrm{mb}$ meridional wind and precipitation is found south of $15^{\circ} \mathrm{N}$ [Figures 5 and 10]. Phase $e_{v r}$ tends to change from no preference at $7.5^{\circ} \mathrm{N}-10^{\circ} \mathrm{N}$ and $0^{\circ}$ to $+120^{\circ}$ (in-phase tendency) at $12.5^{\circ} \mathrm{N}$ before July to $-60^{\circ}$ to $-180^{\circ}$ (out-of-phase tendency) during July-September. This may suggest a seasonal transition of wave-convective interaction, possibly a consequence of seasonal variations in the strength of wave activity (and possibly a southward extension) and the ITCZ.

The contrasting phase-relationship provides a basic description of internal association of waves with convection. Nevertheless, the interpretion of this relationship entirely depends on our understanding of easterly waves's structure based on previous observations and our current knowledge of tropical convection. Generally, a positive correlation between convective heating and temperature is a must for a positive wave-convective coupling, even if a vortex-stretching mechanism is proposed. However, an alternative mechanism may be in effect through the existence of the AEJ. Convective heating tends to maintain the AEJ and easterly waves always weaken it [Thorncroft and Blackburn, 1999]. Hence the interaction between the easterly waves and convection seems to be much more complicated 
than anticipated and is far from being understood. Further studies of these waves' thermal structure and spatial distribution of diabatic heating are required.

As an important synoptic-scale phenomenon readily seen in daily surface and satellite maps, easterly waves are also essential to the diagnosis and prediction of African climate. Their structure, propagation and associated convection and precipitation might be closely related to the seasonal march of the ITCZ rain belt and seasonal cycle existing in the large-scale environment, for instance, the AEJ and low-level Monsoon flow. Sultan and Janicot [2000] described the existence of a "Monsoon jump" in the early summer, and proposed that it may be connected to a concomitant westward-propagating intra-seasonal signal. However, they did not further clarify the properties of this intra-seasonal signal. Le Barbe et al. [2002] suggested that perhaps two different dynamic processes account for the two peaks in precipitation: One is seen near the Gulf of Guinea $\left(\sim 5^{\circ} N\right)$ before July and the other is along $10^{\circ} \mathrm{N}$ between July-September. In addition to their arguements, we speculate that easterly waves might be another essential part in the second peak season. As mentioned, due to the release of dynamic instability in the AEJ, which is also modulated by the convective heating associated with the easterly waves, most intense waves usually develop in this season. They extend their influence to the south and become positively coupled with convection and precipitation. Hence, it is possible for them to effectively organize precipitation and pull the main convective region to the north from the coastal region with the rapid increase of low-level moist Monsoon flow. Tai and Ogura (1987) noted the possible role of tropical easterly waves in the surface confluence line jump during June-July in the tropical eastern Pacific. 
Intraseasonal variations in wave activity and associated convection have been shown in this study [Figures 7,8 and 9]. Understanding these variations could be crucial for exploring the interannual variability in easterly waves and Atlantic hurricane activities. Similar variations may also exist in the large-scale environment such as the AEJ, surface precipitation, and low-level Monsoon flow, etc.. Thorncroft and Rowell [1998] illustrated the existence of intraseasonal variations in the AEJ instability. However, seasonal and latitudinal preference of wave-convective interaction undoubtedly warrants further clarification.

Acknowledgments. The authors would like to thank Dr. Chidong Zhang for his comments. Thanks are also due to Mr. David Bolvin for preparing the TRMM 3B42 data. NCAR/NCEP Reanalysis data were provided by the NOAA-CIRES Climate Diagnostics Center, Boulder,Colorado, USA, from its Web site at http://www.cdc.noaa.gov. This work is supported through the TRMM Science Team under the NASA Headquarters TRMM Program Scientist Dr. Ramesh Kakar. 


\section{References}

Adler, R. F., G. J. Huffman, D. T. Bolvin, S. Curtis and E. J. Nelkin, Tropical rainfall distributions determined using TRMM combined with other satellite and rain gauge information. J. Appl. Meteorol., 39, 2007-2023, 2000.

Burpee, R. W., The origin and structure of easterly waves in the lower troposphere of North Africa. J. Atmos. Sci., 29, 77-90, 1972.

Burpee, R. W., Characteristics of the North African easterly waves during the summers of 1968 and 1969. J. Atmos. Sci., 31, 1556-1570, 1974.

Burpee, R. W., Some features of synoptic-scale waves based on compositing analysis of GATE data. Mon. Weather Rev., 103, 921-925, 1975.

Carlson, T. N., Synoptic histories of three African disturbances that developed into Atlantic hurricanes. Mon. Weather Rev., 97, 256-276, 1969a.

Carlson, T. N., Some remarks on African disturbances and their progress over the tropical Atlantic. Mon. Weather Rev., 97, 716-726, $1969 \mathrm{~b}$.

Chen, Y. L. and Y. Ogura, Modulation of convective activity by large-scale flow patterns observed in GATE. J. Atmos. Sci., 39, 1260-1279, 1982.

Diedhiou, A, S. Janicot, A. Viltard, and P. de Felice, Evidence of two regimes of easterly waves over West Africa and the tropical Africa. Geophys. Res. Lett., 25, 2805-2808, 1998.

Diehiou, A., S. Janicot, A. Viltard, P. De Felice, and H. Laurent, Easterly waves regimes and associated convection over West Africa and the tropical Atlantic: Results from the NCEP/NCAR and ECMWF reanalyses. Clim. Dyn., 15, 795-822, 1999. 
Diehiou, A., S. Janicot, A. Viltard, and P. De Felice, Composite patterns of easterly disturbances over West Africa and the tropic Atlantic: a climatology from the 1979-95 NCEP/NCAR reanalyses. Clim. Dyn., 18, 241-253, 2001.

Duvel, J. P., Convection over tropical Africa and the Atlantic Ocean during northern summer. Part II: Modulation by easterly waves. Mon. Weather Rev., 118, 1855-1868, 1990.

Gilman, D. L., F. J. Fuglister, and J. M. Mitchell, Jr., On the power spectrum of "red noise". J. Atmos. Sci., 20, 182-184, 1963.

Grist, J. P., Easterly waves over Africa. Part I: The seasonal cycle and contrasts between wet and dry years. Mon. Weather Rev., 130, 197-211, 2002.

Gu, G., and C. Zhang, Westward-propagating synoptic-scale disturbances and the ITCZ. J. Atmos. Sci., 59, 1062-1075, 2002.

Kalnay, E., and Co-authors, The NCEP/NCAR 40-year reanalysis project. Bull. Am. Meteorol. Soc., 77, 437-471, 1996.

Kummerow, C., and Co-authors, The status of the Tropical Rainfall Measuring Mission (TRMM) after two years in orbit. J. Appl. Meteorol., 39, 1965-1982, 2000.

Landsea, C. W., A climatology of intense (or major) Atlantic hurricanes. Mon. Weather Rev., 121, 1703-1713, 1993.

Lau, K. M. and H. Weng, Climate signal detection using wavelet transform: How to make a time series sing. Bull. Am. Meteorol. Soc., 76, 2391-2402, 1995.

Le Barbe, L., T. Lebel, and D. Tapsoba, Rainfall variability in West Africa during the years 1950-90. J. Clim., 15, 187-202, 2002. 
Moustaoui, M., J.-F. Royer, and F. Chauvin, African easterly wave activity in a variable resolution GCM. Clim. Dyn., 19, 289-301, 2002.

Redelsperger, J.-L., A. Diongue, A. Diedhiou, J.-P. Ceron, M. Diop, J.-F Gueremy, and J.P. Lafore, Multi-scale description of a Sahelian synoptic weather system representative of the West African Monsoon, Quart. J. Roy. Meteorol. Soc., 128, 1229-1257, 2002.

Reed, R. J., D. C. Norquist, and E. E. Recker, The structure and properties of African wave disturbances as observed during Phase III of GATE. Mon. Weather Rev., 105, $317-333,1977$.

Smith, S. R., D. M. Lehler, and K. V. Verzone, Quantifying uncertainties in NCEP reanalyses using high-quality research vessel observations. J. Clim., 14, 4062-4072, 2001.

Sultan, B. and S. Janicot, Abrupt shift of the ITCZ over West Africa and intra-seasonal variability. Geophys. Res. Lett., 27, 3353-3356, 2000.

Tai, K.-S., and Y. Ogura, An observational study of easterly waves over the eastern Pacific in the northern summer using FGGE data. J. Atmos. Sci., 44, 339-361, 1987.

Thorncroft, C. D., and M. Blackburn, Maintenanceof the African easterly jet. Quart. J. Roy. Meteorol. Soc., 125, 763-786, 1999.

Thorncroft, C. D., and D. P. Rowell, Interannual variability of African wave activity in a general circulation model. Int. J. Climatol., 18, 1305-1323, 1998.

Torrence C., and G. P. Compo, 1998: A practical guide to wavelet analysis. Bull. Am. Meteorol. Soc., 79, 61-78, 1998.

Wheeler, M., and G. N. Kiladis, Convectively coupled equatorial waves: Analysis of clouds and temperature in the wavenumber-frequency domain. J. Atmos. Sci., 56, 374-399, 1999. 
Figure 1. Mean power spectra of $850 \mathrm{mb}$ meridional winds ( $P_{v}$, solid lines) and precipitation $\left(P_{r}\right.$, dashed lines) between $5^{\circ} \mathrm{N}-20^{\circ} \mathrm{N}$ and $5^{\circ} \mathrm{W}-2.5^{\circ} \mathrm{E}$ during June - October.

Figure 2. Mean cross-spectra $\left(C_{v r}\right)$ of $850 \mathrm{mb}$ meridional winds and precipitation between $5^{\circ} \mathrm{N}-20^{\circ} \mathrm{N}$ and $5^{\circ} \mathrm{W}-2.5^{\circ} \mathrm{E}$ during June - October. Megenta lines are for 1998, cyan lines for 1999, red lines for 2000, green lines for 2001 and blue lines for 2002 . 
Figure 3. Mean spectra of $850 \mathrm{mb}$ meridional winds $\left(P_{v}\right.$, solid lines) and precipitation $\left(P_{r}\right.$, dashed lines) within a period range of $2.56-6.08$ days (vertical lines in Fig. 2a) between $5^{\circ} \mathrm{W}-2.5^{\circ} \mathrm{E}$ during June - October as function of latitude.

Figure 4. Mean cross-spectra $\left(C_{v r}\right)$ of $850 \mathrm{mb}$ meridional winds and precipitation within a period range of $2.56-6.08$ days between $5^{\circ} \mathrm{W}-2.5^{\circ} \mathrm{E}$ during June October as function of latitude. Megenta lines are for 1998, cyan lines for 1999, red lines for 2000, green lines for 2001 and blue lines for 2002 .

Figure 5. Number distribution of grid points as function phase-difference $\left(\right.$ Phase $\left._{v r}\right)$ between $850 \mathrm{mb}$ meridional winds and precipitation within a period range of $2.56-6.08$ days between $5^{\circ} \mathrm{W}-2.5^{\circ} \mathrm{E}$ during July-September at six various latitudes: (a) for $7.5^{\circ} \mathrm{N}$, (b) for $10^{\circ} \mathrm{N}$, (c) for $12.5^{\circ} \mathrm{N}$, (d) for $15^{\circ} \mathrm{N}$, (e) for $17.5^{\circ} \mathrm{N}$, and (f) for $20^{\circ} \mathrm{N}$, respectively. 
Figure 6. Cross-spectra $\left(C_{v r}\right)$ vs. phase-difference $\left(\right.$ Phase $\left._{v r}\right)$ of $850 \mathrm{mb}$ meridional winds and precipitation within a period range of $2.56-6.08$ days between $5^{\circ} \mathrm{W}-2.5^{\circ} \mathrm{E}$ during June - October at six various latitudes: (a) for $7.5^{\circ} \mathrm{N}$, (b) for $10^{\circ} \mathrm{N}$, (c) for $12.5^{\circ} \mathrm{N}$, (d) for $15^{\circ} \mathrm{N}$, (e) for $17.5^{\circ} \mathrm{N}$, and (f) for $20^{\circ} \mathrm{N}$, respectively.

Figure 7. 5-yr-mean wavelet spectra of $850 \mathrm{mb}$ meridional winds ( $P_{v}$; solid line) and precipitation $\left(P_{r} ;\right.$ dashed line $)$, and wavelet cross-spectrum $\left(C_{v r} ;\right.$ dashdot line $)$ within a period range of $2.56-6.08$ days between $5^{\circ} \mathrm{N}-20^{\circ} \mathrm{N}, 5^{\circ} \mathrm{W}-2.5^{\circ} \mathrm{E}$ as function of time.

Figure 8. Mean spectra of $850 \mathrm{mb}$ meridional winds ( $P_{v}$; solid lines), precipitation $\left(P_{r}\right.$; dashed lines), and cross spectra $\left(C_{v r}\right)$ within a period range of $2.56-6.08$ days within a domain of $5^{\circ} \mathrm{N}-20^{\circ} \mathrm{N}$ and $5^{\circ} \mathrm{W}-2.5^{\circ} \mathrm{E}$ as function of time. 
Figure 9. Mean spectra of $850 \mathrm{mb}$ meridional winds ( $P_{v}$; solid lines) and precipitation $\left(P_{r}\right.$; dashed lines) within a period range of $2.56-6.08$ days between $5^{\circ} \mathrm{W}-2.5^{\circ} \mathrm{E}$ as function of time. Left panel is for $15^{\circ} \mathrm{N}-20^{\circ} \mathrm{N}$, and right panel for $5^{\circ} \mathrm{N}-10^{\circ} \mathrm{N}$.

Figure 10. Same as in Figure 5 but for May-June.

Figure 11. The $850 \mathrm{mb}$ composite wind field (wind vectors; $\mathrm{ms}^{-1}$ ), $700 \mathrm{mb}$ composite vertical velocity (countors; $\omega=\frac{d P}{d t}$, the interval is $0.006 \mathrm{pa} \mathrm{s}^{-1}$ ), and rainfall anomalies (shades; $m m d a y^{-1}$ ) related to reference points located at (a) $10^{\circ} \mathrm{N}, 0^{\circ} \mathrm{E}$ and (b) $17.5^{\circ} \mathrm{N}, 0^{\circ} \mathrm{E}$. 

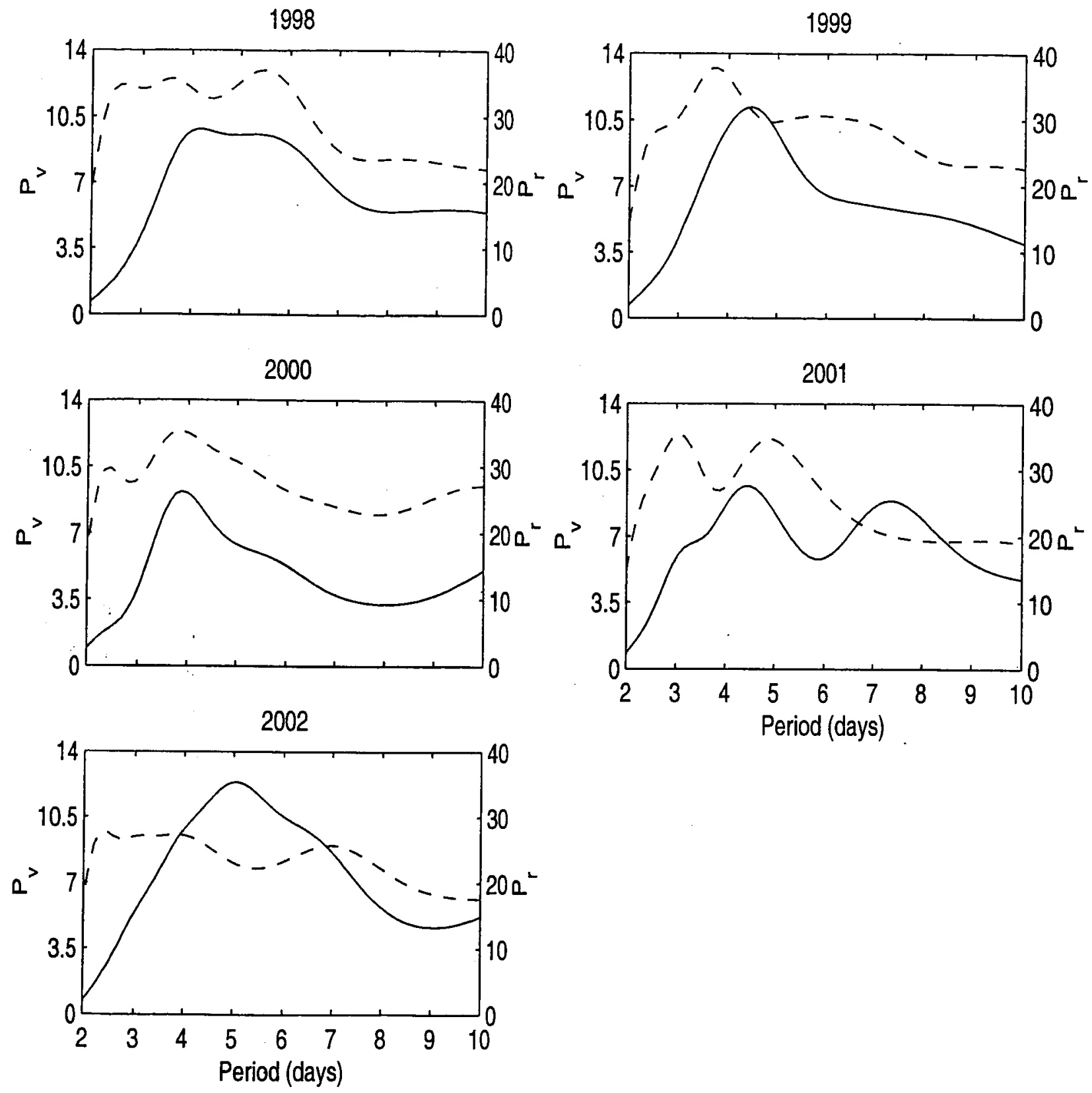

Figure 1: Mean power spectra of $850 \mathrm{mb}$ meridional winds $\left(P_{v}\right.$, solid lines) and precipitation $\left(P_{r}\right.$, dashed lines) between $5^{\circ} \mathrm{N}-20^{\circ} \mathrm{N}$ and $5^{\circ} \mathrm{W}-2.5^{\circ} \mathrm{E}$ during June - October. 


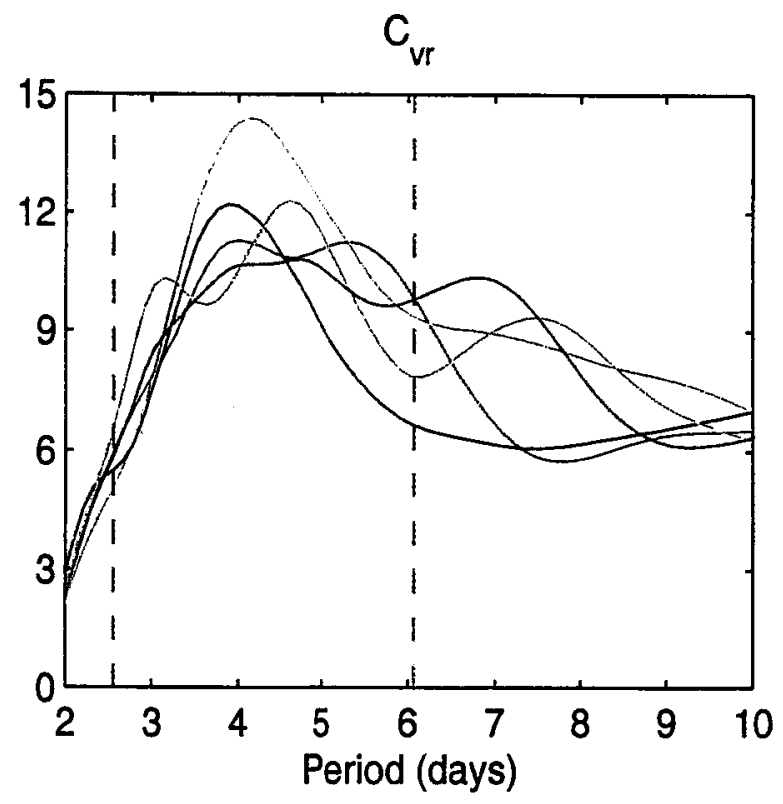

Figure 2: Mean cross-spectra $\left(C_{v r}\right)$ of $850 \mathrm{mb}$ meridional winds and precipitation between $5^{\circ} \mathrm{N}-20^{\circ} \mathrm{N}$ and $5^{\circ} \mathrm{W}-2.5^{\circ} \mathrm{E}$ during June - October. Megenta lines are for 1998, cyan lines for 1999, red lines for 2000, green lines for 2001 and blue lines for 2002 . 

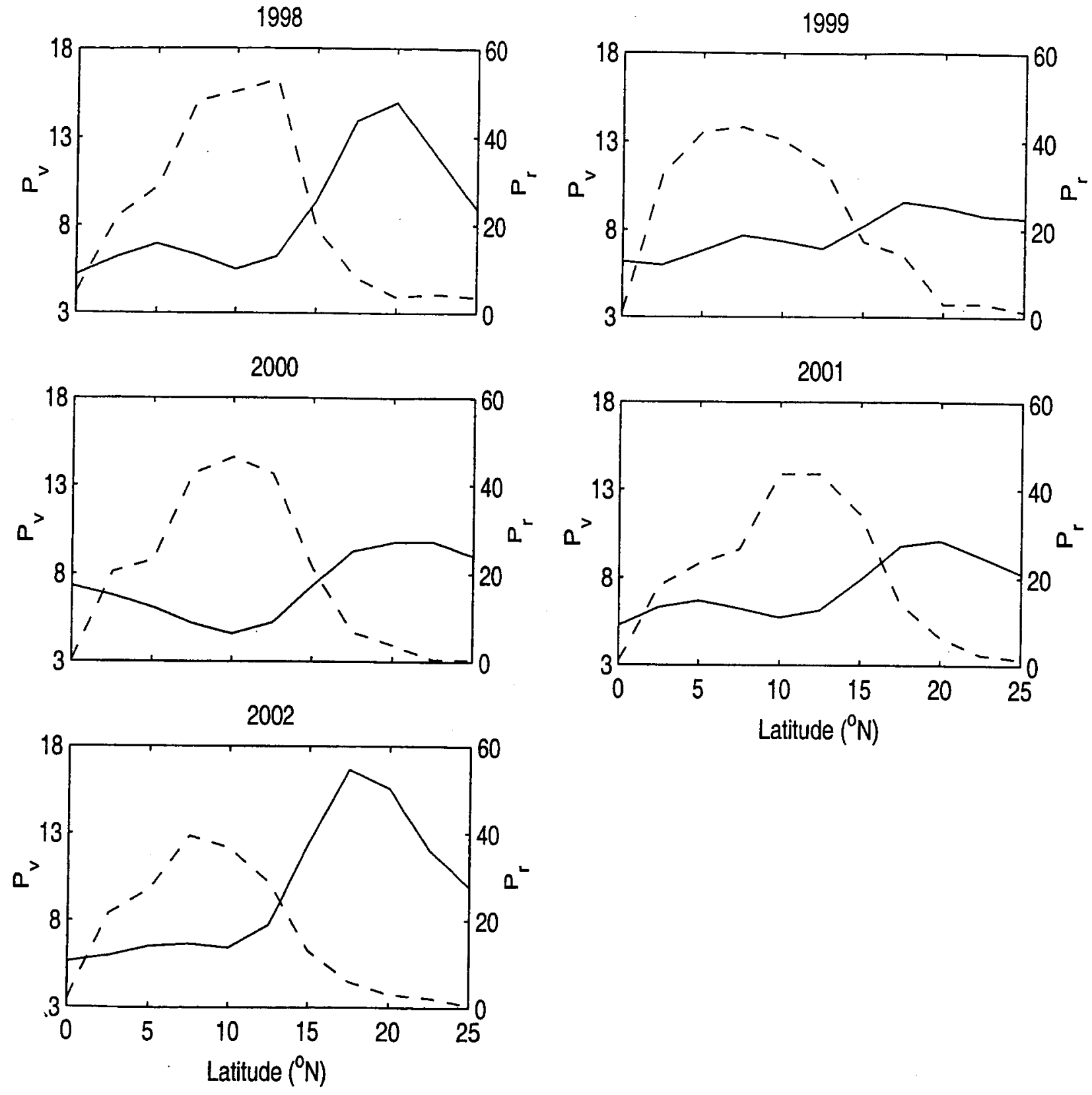

Figure 3: Mean spectra of $850 \mathrm{mb}$ meridional winds $\left(P_{v}\right.$, solid lines) and precipitation $\left(P_{r}\right.$, dashed lines) within a period range of 2.56 - 6.08 days (vertical lines in Fig. 2a) between $5^{\circ} \mathrm{W}-2.5^{\circ} \mathrm{E}$ during June - October as function of latitude. 


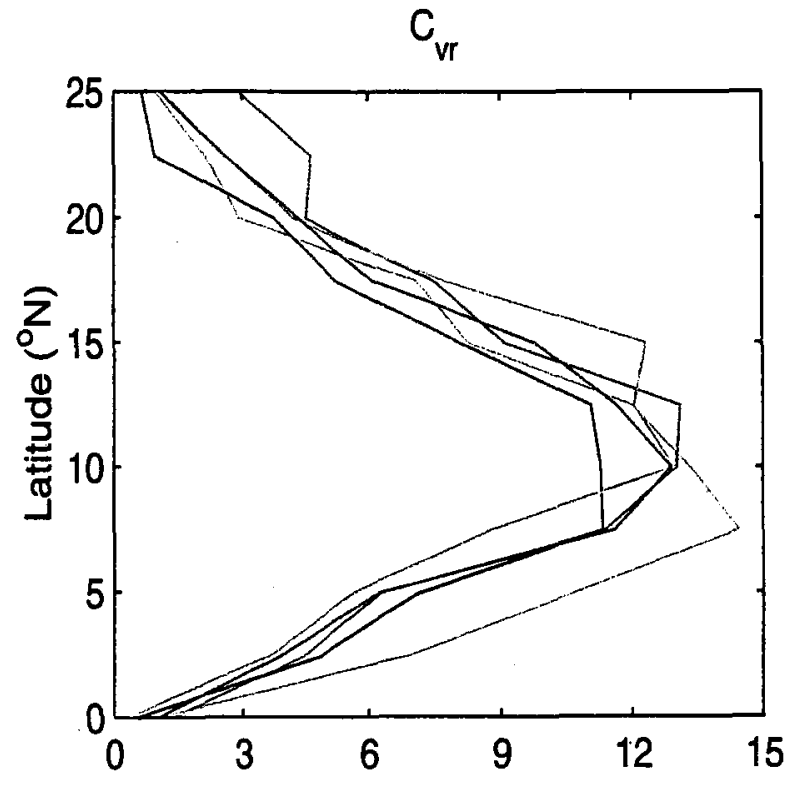

Figure 4: Mean cross-spectra $\left(C_{v r}\right)$ of $850 \mathrm{mb}$ meridional winds and precipitation within a period range of $2.56-6.08$ days between $5^{\circ} \mathrm{W}-2.5^{\circ} \mathrm{E}$ during June - October as function of latitude. Megenta lines are for 1998, cyan lines for 1999, red lines for 2000, green lines for 2001 and blue lines for 2002 . 
(a)

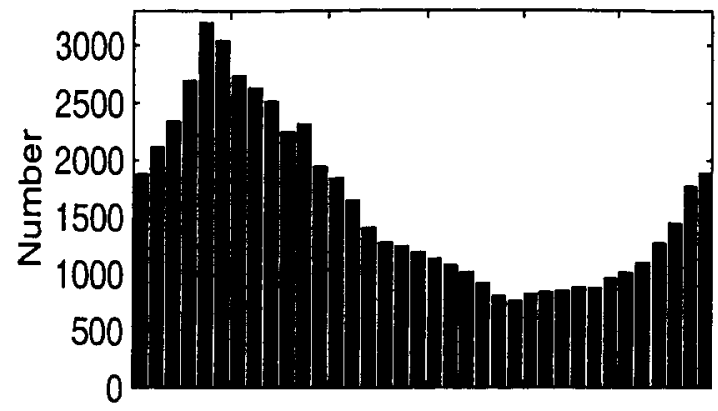

(c)

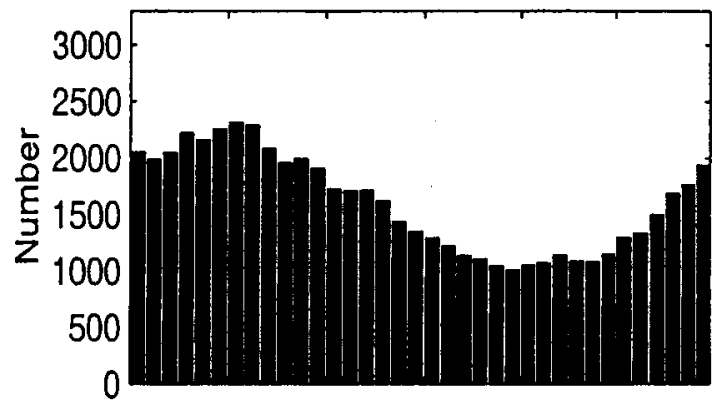

(e)

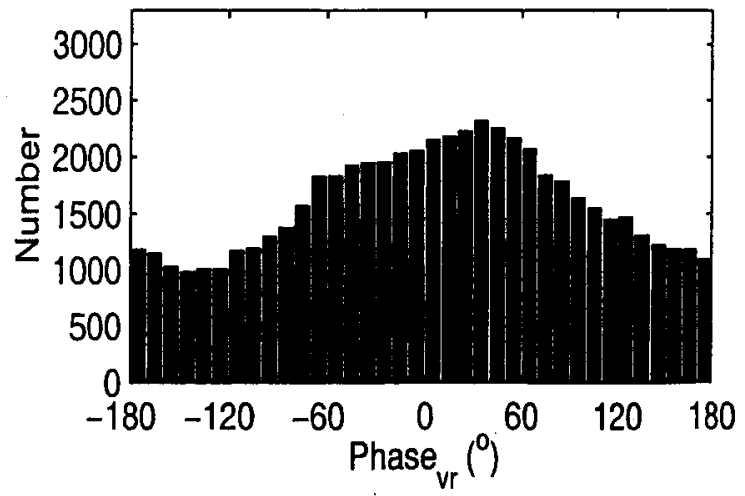

(b)

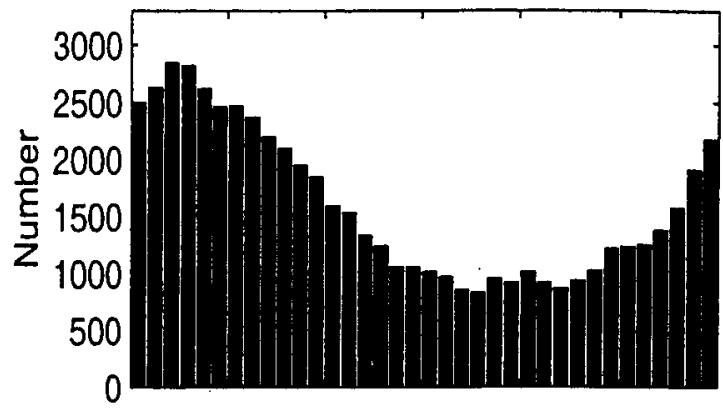

(d)

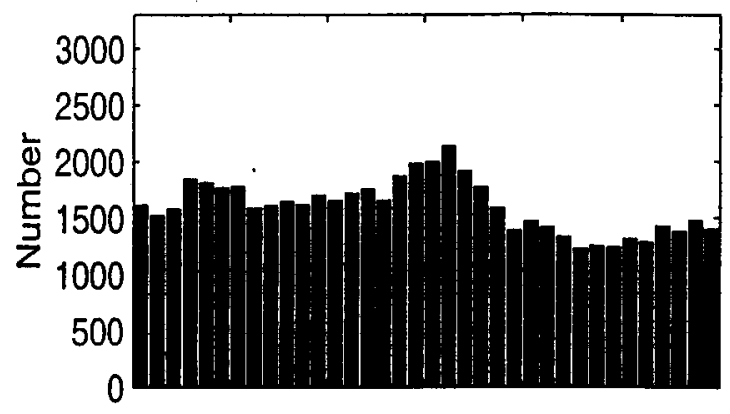

(f)

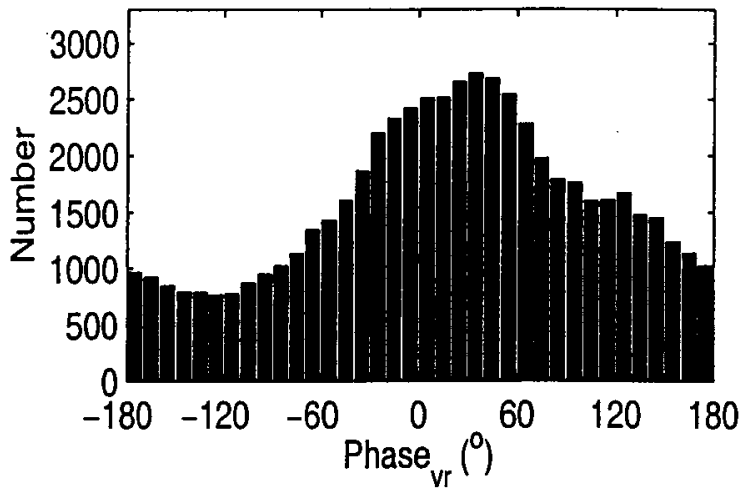

Figure 5: Number distribution of grid points as function of phase-difference ( Phase $\left._{v r}\right)$ between $850 \mathrm{mb}$ meridional winds and precipitation within a period of $2.56-6.08$ days between $5^{\circ} \mathrm{W}-2.5^{\circ} \mathrm{E}$ during July-September at six various latitudes: (a) for $7.5^{\circ} \mathrm{N}$, (b) for $10^{\circ} \mathrm{N}$, (c) for $12.5^{\circ} \mathrm{N}$, (d) for $15^{\circ} \mathrm{N}$, (e) for $17.5^{\circ} \mathrm{N}$, and (f) for $20^{\circ} \mathrm{N}$, respectively. 
(a)

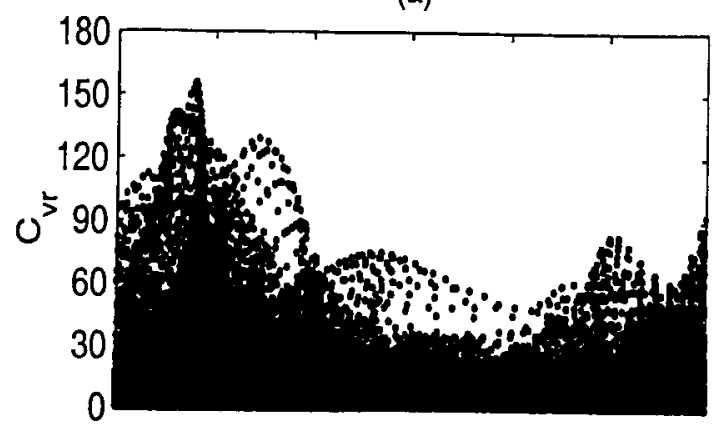

(c)

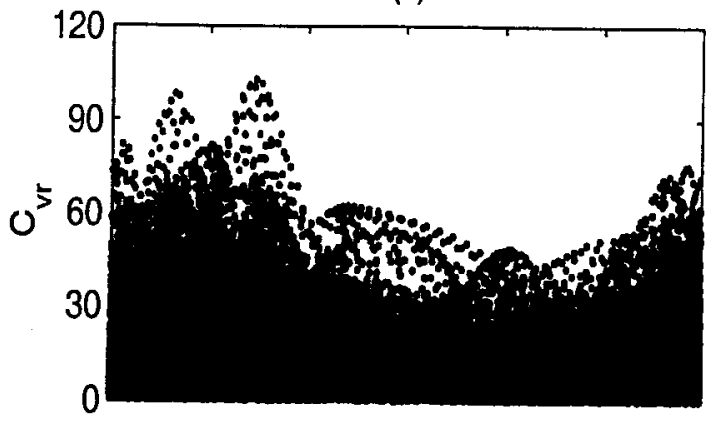

(e)

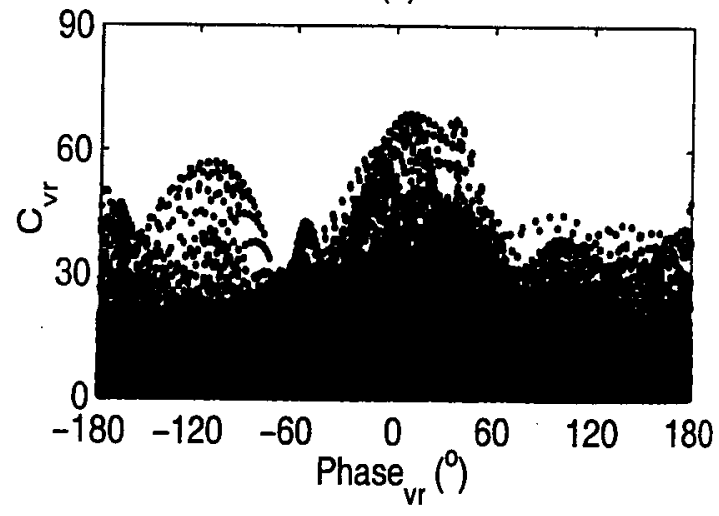

(b)

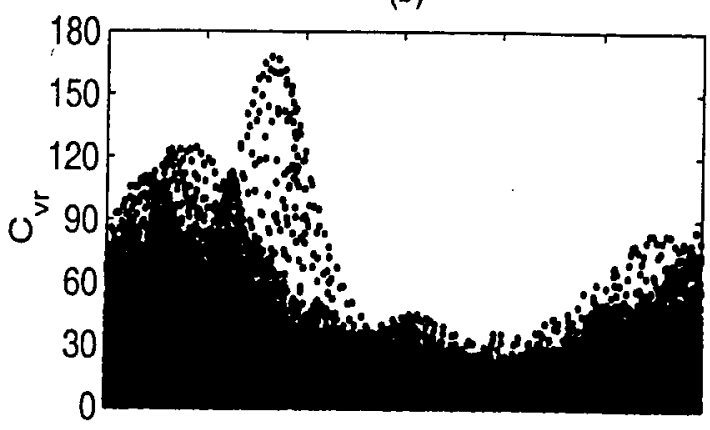

(d)

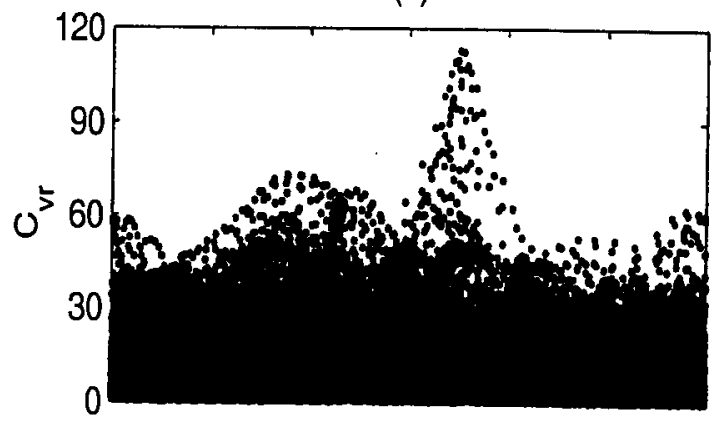

(f)

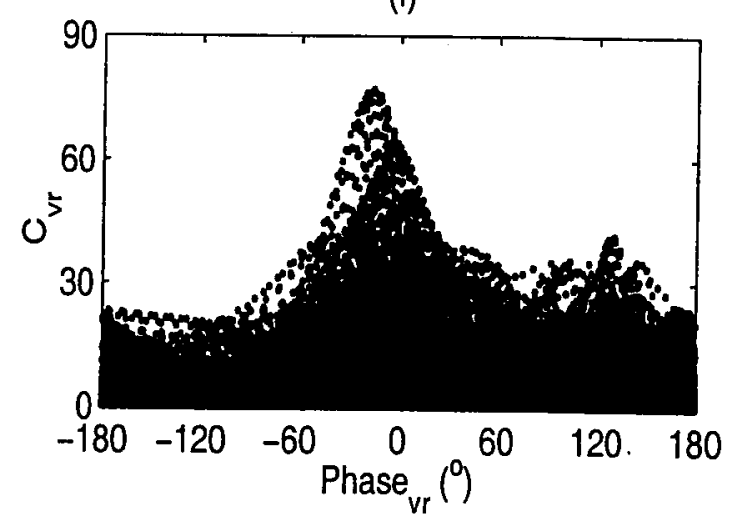

Figure 6: Cross-spectra $\left(C_{v r}\right)$ vs. phase-difference (Phase ${ }_{v r}$ ) of $850 \mathrm{mb}$ meridional winds and precipitation within a period of $2.56-6.08$ days between $5^{\circ} \mathrm{W}-2.5^{\circ} \mathrm{E}$ during June October at six various latitudes: (a) for $7.5^{\circ} \mathrm{N}$, (b) for $10^{\circ} \mathrm{N}$, (c) for $12.5^{\circ} \mathrm{N}$, (d) for $15^{\circ} \mathrm{N}$, (e) for $17.5^{\circ} \mathrm{N}$, and (f) for $20^{\circ} \mathrm{N}$, respectively. 


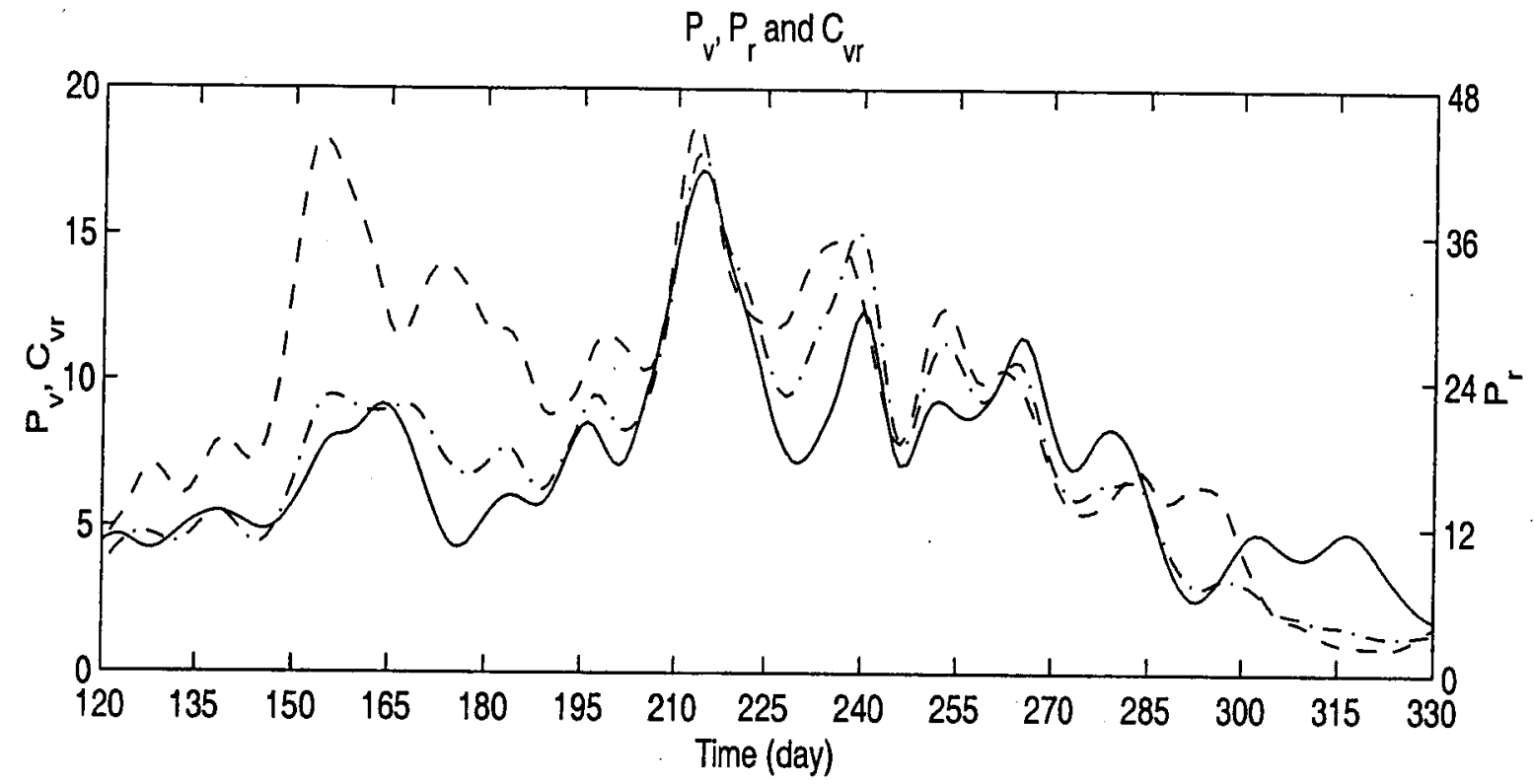

Figure 7: 5-yr-mean wavelet spectra of $850 \mathrm{mb}$ meridional winds ( $P_{v}$; solid line) and precipitation $\left(P_{r}\right.$; dashed line $)$, and wavelet cross-spectrum $\left(C_{v r} ;\right.$ dashdot line $)$ within a period range of $2.56-6.08$ days between $5^{\circ} \mathrm{N}-20^{\circ} \mathrm{N}, 5^{\circ} \mathrm{W}-2.5^{\circ} \mathrm{E}$ as function of time. 


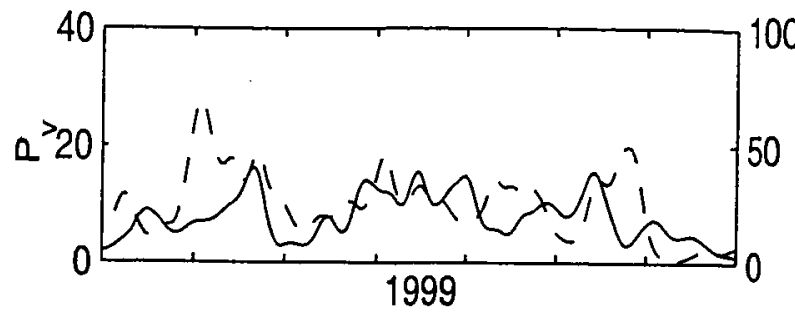

100
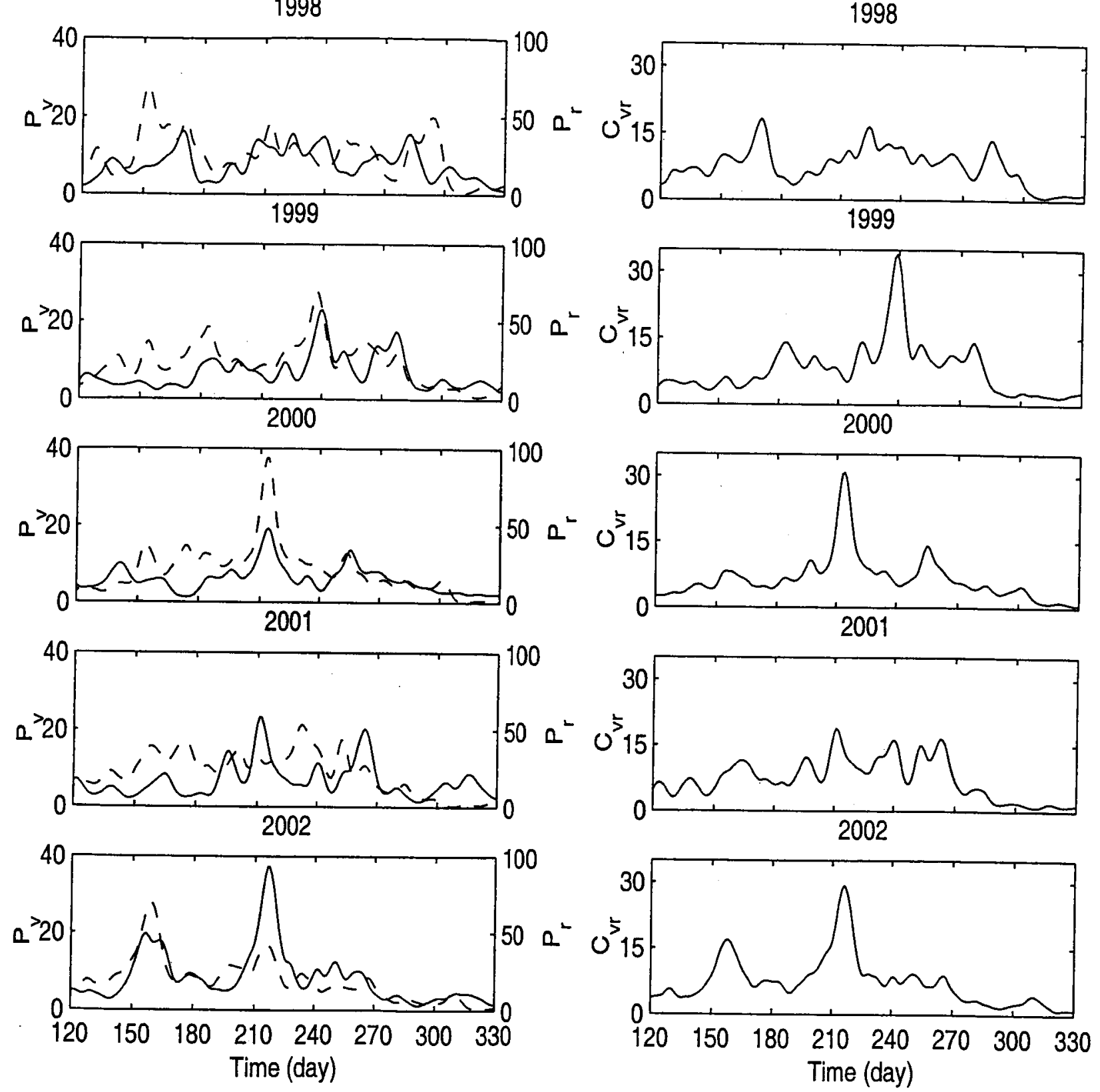

Figure 8: Mean spectra of $850 \mathrm{mb}$ meridional winds ( $P_{v}$; solid lines), precipitation $\left(P_{r}\right.$; dashed lines), and cross spectra $\left(C_{v r}\right)$ within a period range of $2.56-6.08$ days within a domain of $5^{\circ} \mathrm{N}-20^{\circ} \mathrm{N}$ and $5^{\circ} \mathrm{W}-2.5^{\circ} \mathrm{E}$ as function of time. 
1998
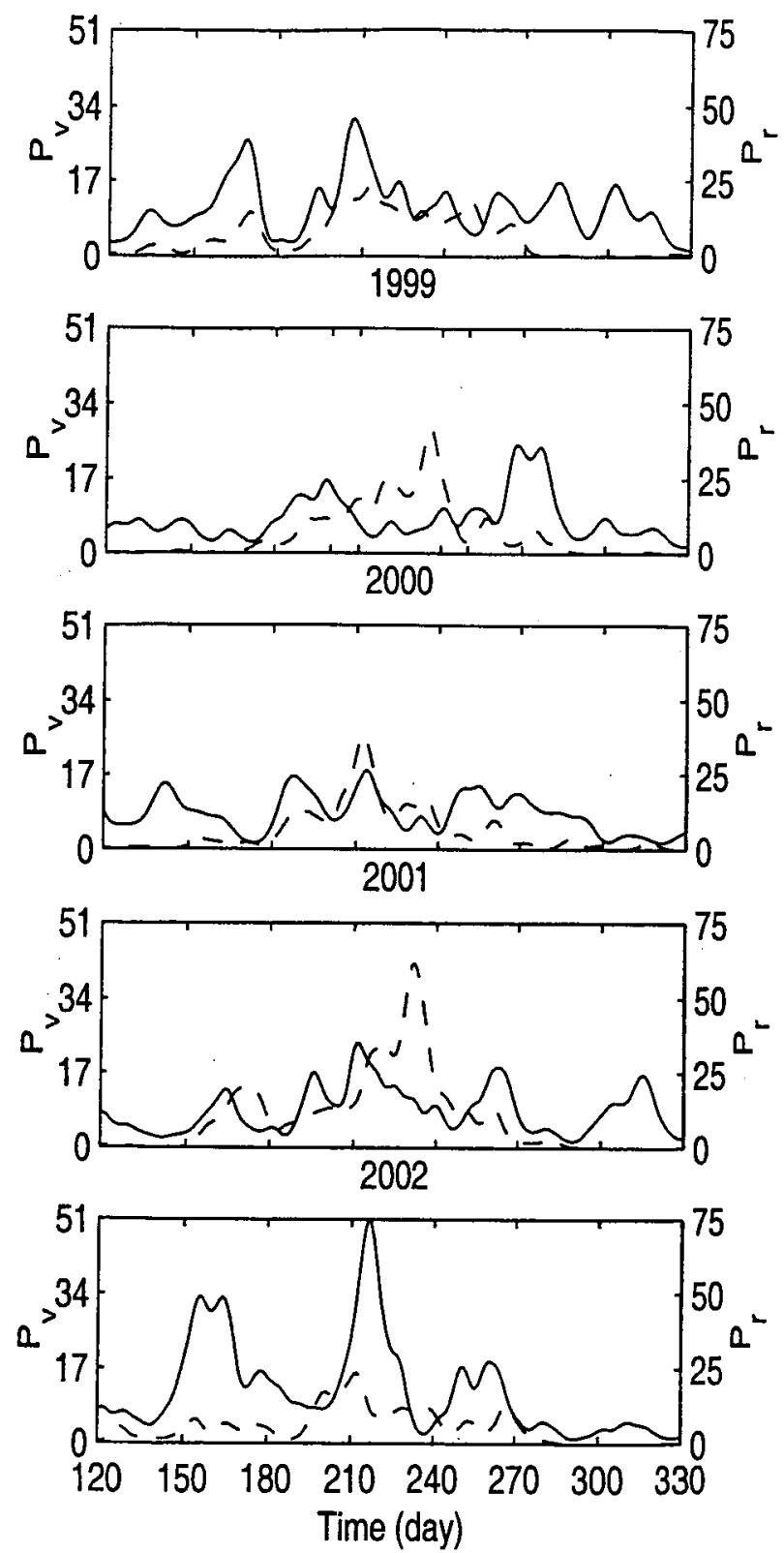

1998
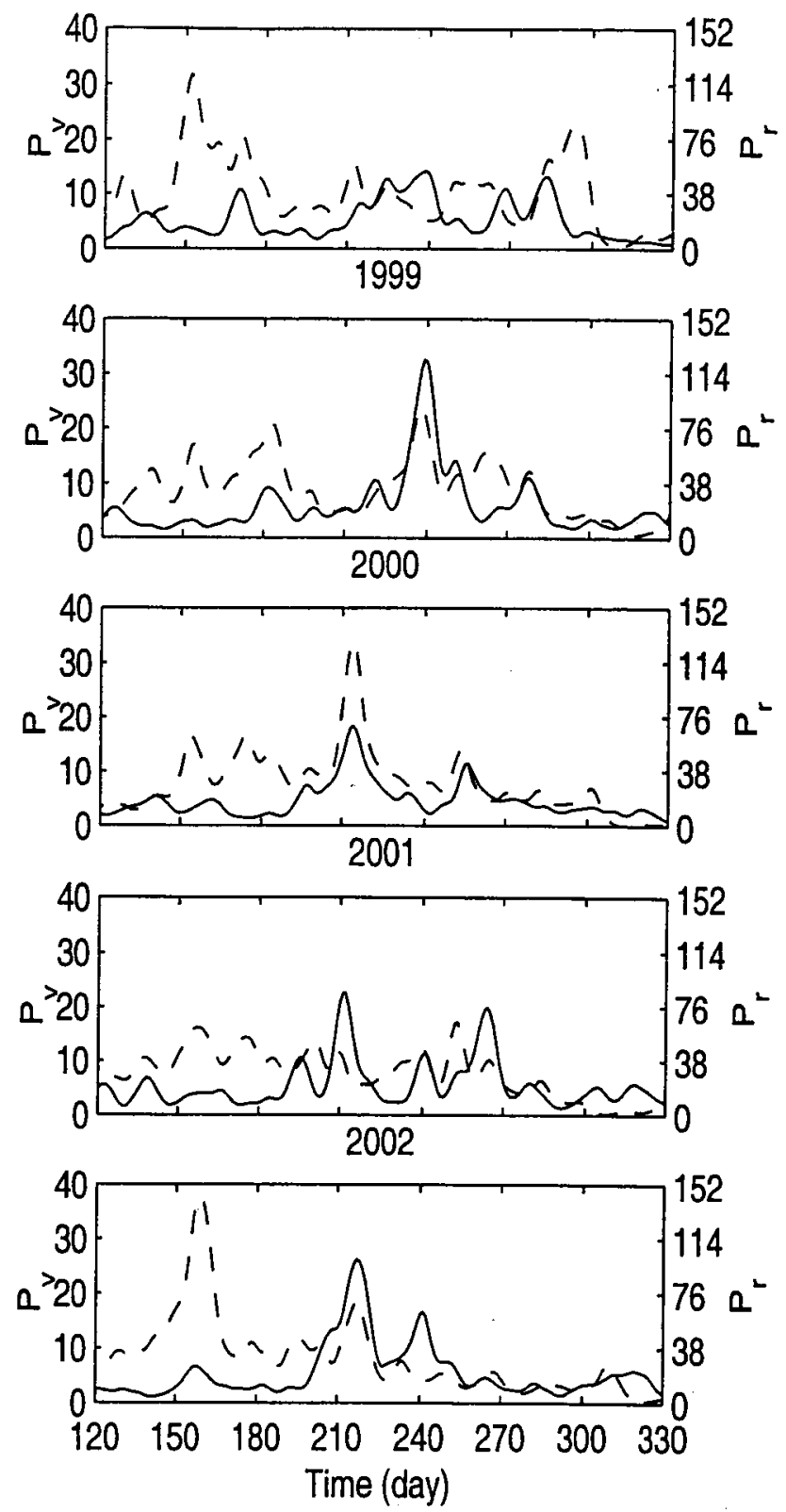

Figure 9: Mean spectra of $850 \mathrm{mb}$ meridional winds $\left(P_{v}\right.$; solid lines) and precipitation $\left(P_{r}\right.$; dashed lines) within a period range of $2.56-6.08$ days between $5^{\circ} \mathrm{W}-2.5^{\circ} \mathrm{E}$ as function of time. Left panel is for $15^{\circ} \mathrm{N}-20^{\circ} \mathrm{N}$, and right panel for $5^{\circ} \mathrm{N}-10^{\circ} \mathrm{N}$. 
(a)

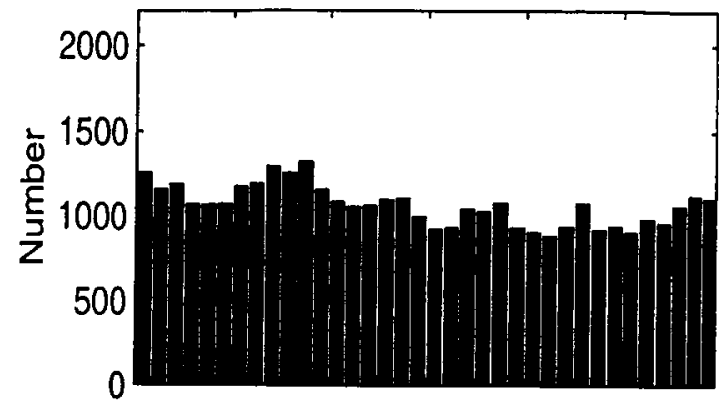

(c)

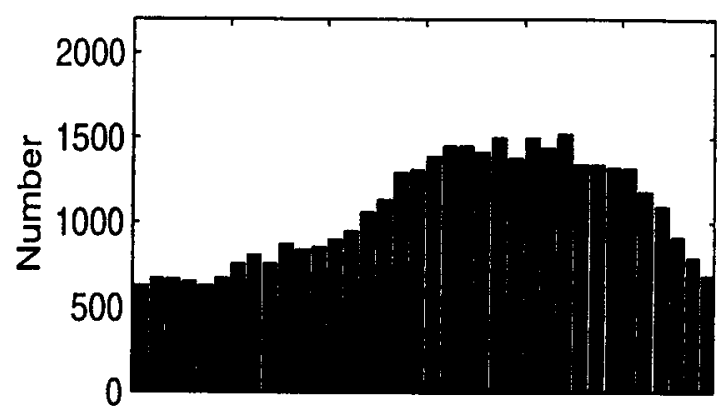

(e)

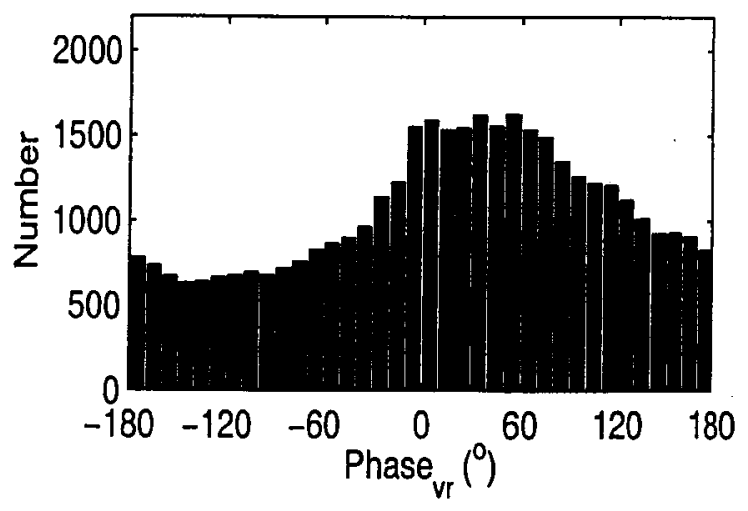

(b)

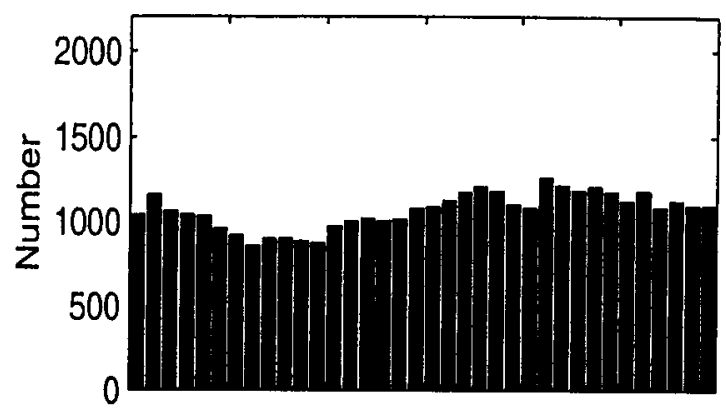

(d)

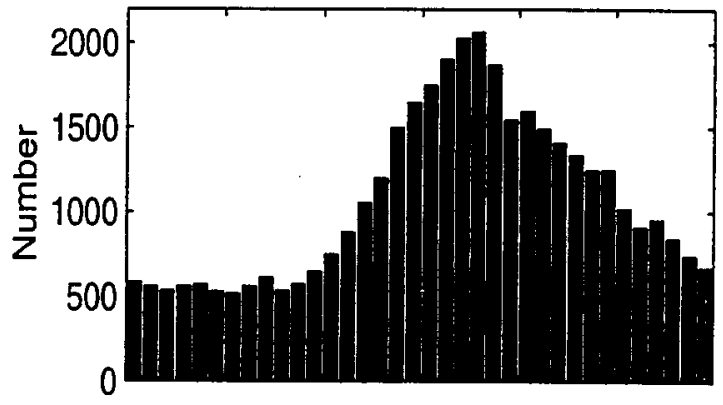

(f)

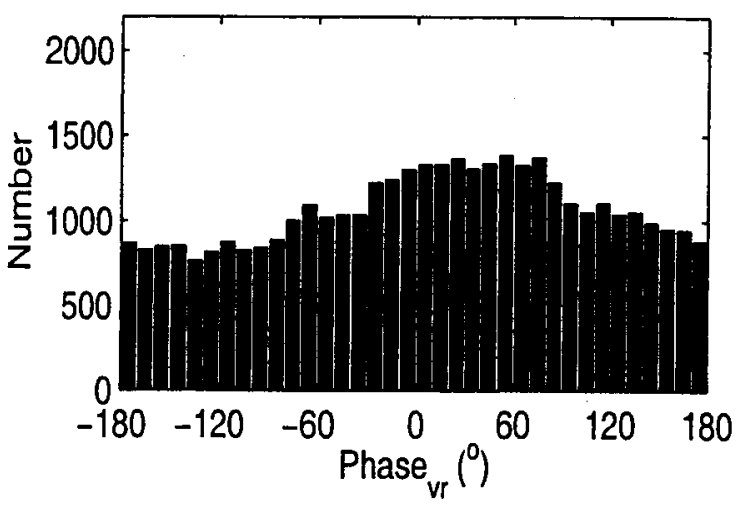

Figure 10: Same as in Fig. 5 but for May-June. 
(a)

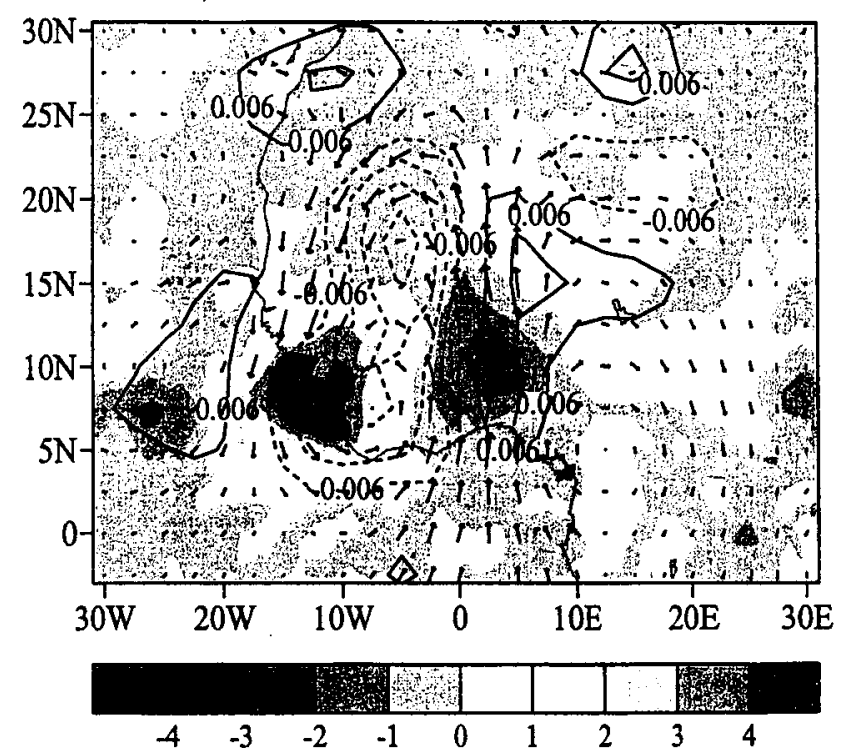

(b)

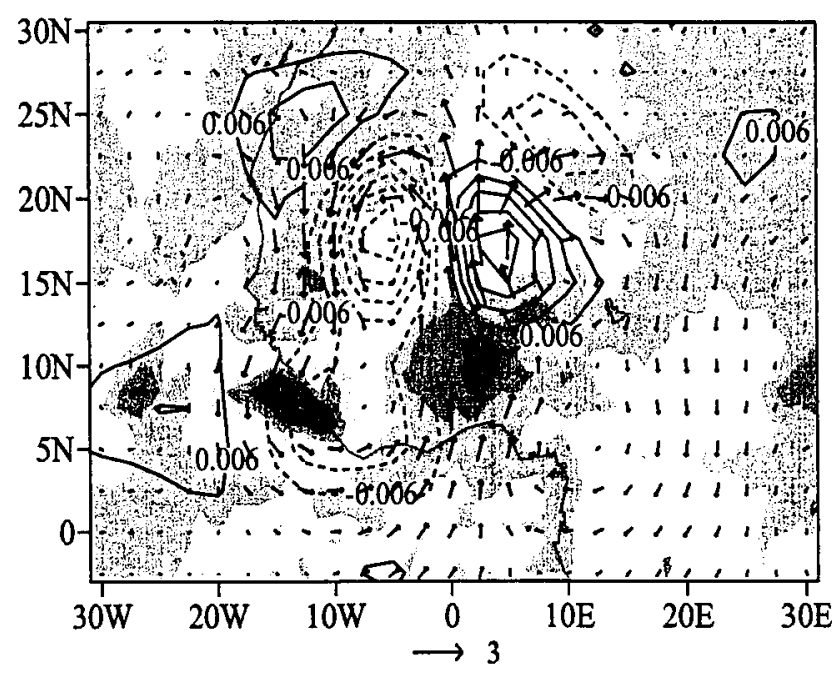

Figure 11: The $850 \mathrm{mb}$ composite wind field (wind vectors; $\mathrm{ms}^{-1}$ ), $700 \mathrm{mb}$ composite vertical velocity (countors; $\omega=\frac{d P}{d t}$, the interval is $0.006 \mathrm{pa} \mathrm{s}^{-1}$ ), and rainfall anomalies (shades; $\mathrm{mm}$ $d a y^{-1}$ ) related to reference points located at (a) $10^{\circ} \mathrm{N}, 0^{\circ} \mathrm{E}$ and (b) $17.5^{\circ} \mathrm{N}, 0^{\circ} \mathrm{E}$. 